\title{
Memória, paz e reconciliação: entrevista com Camilo Posso
}

\author{
Memory, peace and reconciliation: interview with Camilo Posso
}

Enviado em: 04/06/2017

Aceito em: 04/06/2017

FERREIRA, Letícia Mazzucchi ${ }^{1}$

\begin{abstract}
Resumo:
O tema da justiça de transição tem sido de suma importância para os países latino-americanos nas últimas décadas. Nesse contexto, o direito à verdade, à reparação e à justiça tem sido debatido e alcançado de diferentes maneiras e em diferentes níveis em cada um dos países afetados pela violência de Estado durante o século XX. Em meio a tão delicados debates, o tema da reconciliação como um pilar para a verdade e para a justiça apresenta-se na proposta desenvolvida pelo Centro de Memoria para a Paz, de Bogotá, como um desafiador motor de reconstrução social em um país ainda profundamente marcado por conflitos violentos. Sobre esse tema, nos fala Camilo González Posso, diretor do Centro, em entrevista concedida à professora Maria Letícia Mazzucchi Ferreira, no dia 20 de novembro de 2015, que contou com apoio da FAPERGS.
\end{abstract}

Palavras-chave: Justiça de transição, reconciliação, América Latina

\begin{abstract}
:
${ }^{1}$ Professora Associada da Universidade Federal de Pelotas. Atua como docente e pesquisadora na área de Patrimônio, principalmente nos seguintes temas: patrimônio industrial, patrimônio imaterial, políticas públicas de patrimônio, memória, museus. É docente no Programa de Pós-Graduação (Mestrado/Doutorado) em Memória Social e Patrimônio Cultural da Universidade Federal de Pelotas.
\end{abstract}


The subject of transitional justice has been very important to Latin American countries in recent decades. In this context, the right of truth, reparation and justice has been debated and pursued in different ways and at different levels in each of the countries affected by state violence during the twentieth century. Between of such delicate debates, the topic of reconciliation as an important point for truth and justice, is presented in the proposal developed by the "Centro de Memoria para a Paz" in Bogotá as a challenge for social reconstruction in a country still deeply marked by violent conflicts. About this subject, Camilo González Posso, director of the Center, tells us in a interview submitted to the teacher Maria Letícia Mazzucchi Ferreira, on November 20th, 2015, with support of FAPERGS.

Keywords: Transitional justice, reconciliation, Latin America

Gostaria de saber como as instituições culturais abordam a memória e quais as relações com a comunidade, com o público. No processo de constituição do Centro de Memória, como entrou o tema da paz e da reconciliação e como isso foi interpretado pelas pessoas?

O Centro de Memória para a Paz - INDEPAZ é fruto de uma proposta que elaboramos através do Instituto de Estudos para o Desenvolvimento e para a Paz, que eu presido. Havíamos desenvolvido, antes de 2003, uma proposta de memorial que voltamos a apresentar em 2008, como Centro de Memória e Paz. Foi muito bem aceito apesar da resistência por parte do Governo, na época presidido por Uribe Vélez, que considerava que uma vez que na Colômbia já não havia conflito armado, nem tampouco guerrilhas, terroristas ou paramilitares, já que nessa altura esses grupos estavam desmobilizados, não haveria sentido em se falar de acordo de paz e muito menos de memória a partir do conflito, segundo ele inexistente. Entretanto, Bogotá é um local historicamente de prefeituras independentes, de esquerda, processo que se inicia na primeira década do século, com um discurso humanista e de paz. Então, o projeto foi bem aceito e defendido pela Secretaria de Governo no Conselho, para que fosse aprovado. 
As ideias de memória para a paz, ou de memória e paz já estavam no projeto desde o início. A palavra reconciliação foi introduzida pela Secretaria de Governo, que queria um centro de memória e reconciliação, que se inserisse no Parque da Reconciliação, que havia sido estabelecido em 2005, como de fato se fez. Então, podemos dizer que a denominação do museu se deu por razões práticas, mas abarca muitas discussões, porque o conceito de reconciliação tem sido muito polêmico na Colômbia. Há diferentes correntes, hoje no país, em relação a esse conceito. Há, por exemplo, aquela que entende a reconciliação como uma questão individual de perdão, uma decisão pessoal de não odiar e de perdoar aqueles que lhe fizeram mal, e há uma outra perspectiva mais radical, a partir do ponto de vista do movimento das vítimas, que vê a reconciliação como uma consequência futura da paz.

\section{Quais foram os atores sociais mais importantes no processo de elaboração da proposta do Centro?}

Em uma primeira fase foi muito importante o papel das organizações das vítimas. Organizou-se um processo através do qual participaram algumas das mais representativas associações de vítimas, como a Hijos e Hijas por la Memoria (y contra la impunidad), a Reiniciar, que congrega vítimas da Unión Patriótica, a Asfamipaz, que é de familiares de policiais e soldados que sofreram danos durante o conflito, a País Libre, que reúne familiares de sequestrados, entre outras. De maneira muito especial atuaram as organizações de familiares de detidos e desaparecidos, que participaram de forma intensa dessa primeira fase.

A questão central de elaboração para as organizações que participaram do início do projeto era: Qual papel pode ter um centro de memória e a própria memória em uma situação como a colombiana? Isso porque as reivindicações de memória na sociedade colombiana vinham dessas organizações de vítimas, que se integraram ao movimento latino americano que estava no seu auge, assim como aos movimentos europeus, em países como a Espanha e a Alemanha, enfim, em diversos países em finais da década de noventa. Esses movimentos foram acolhidos por essas organizações de vítimas, sobretudo pela juventude colombiana. Inclusive, na equipe inicial do Centro de Memória, um componente muito importante eram os filhos de pessoas que haviam sido assassinadas ou que haviam desaparecido em meio ao 
conflito por razões políticas e eles carregavam uma bagagem impressionante de conhecimento e de paixão, e estavam convencidas de que se teria ali um espaço para reivindicação, para resistência e também para a busca com uma perspectiva distinta.

Este foi o primeiro núcleo de formulação, que contou com o apoio da INDEPAZ (Instituto de Estudios para el Desarrollo y la Paz) e foi desde o início muito intuitiva. O projeto não foi o resultado de uma avaliação do contexto histórico do processo de construção de memória na Colômbia, nem em nível internacional, foi mais uma decisão política, ou seja, de como a reconstrução da memória em meio ao horror poderia ser uma plataforma para a luta pela paz, de como a memória poderia ser o instrumento de um movimento de paz. As organizações tinham a memória como um instrumento, como um componente de um movimento reivindicatório das vítimas. Então, houve um certo encontro a partir de duas perspectivas. O exercício que se fez foi um processo muito interessante, participativo.

O centro de memória foi instalado nos escritórios da INDEPAZ, ONG que eu dirijo, entre 2008 e 2012, quando se inaugurou o edifício. Como me pediram para dirigir o projeto, eu ofereci as instalações da INDEPAZ para facilitar o funcionamento e reduzir os custos. Isso permitiu que o período de construção da sede do Centro se tornasse um tempo de elaboração, debate e intercâmbio entre diversos setores sociais, ao mesmo tempo em que foi um período para a realização de atividades de memória.

Nessa época, desenvolvemos uma campanha que se chamou "Tierra Sembrada de Memoria" (Terra semeada de memórias). Foi uma convocação para que vítimas, cidadãos e organizações sociais trouxessem terra para a construção do edifício. De maneira simbólica, começamos a receber pequenas porções de terra em urnas que foram depositadas nas ruas, nos colégios, nas Universidades, nos museus, em eventos públicos. Nessas urnas as pessoas deixavam seu testemunho e sua amostra de terra. Alguns grupos não somente entregavam testemunhos, mas também documentos, fotografias, enfim, material mais importante, digamos. Essa terra se incorporou ao edifício e hoje forma parte do memorial, que é o monumento central do local. Ali se encontram plasmadas essas porções de terra, todas as suas histórias e à medida que íamos construindo o edifício, começaram a haver, na sua parte externa, na pequena praça da parte norte, cerimônias a cada quinze dias, para as quais 
vítimas, e pessoas de todos os estratos sociais traziam mais porções de terra. Convidamos também aos jovens para que trouxessem terra de memória com sentido de futuro. Então, todo o movimento de jovens trouxe porções de terra e também mensagens de paz e em memória das vítimas. Dessa forma, "Tierra Sembrada de Memoria" foi como um lema para nós nessa fase inicial.

\section{A memória é sempre entendida como uma reconstrução do pasado? Aquí é como um instrumento para a afirmação da dignidade, das demandas, ou seja, é algo do presente?}

Creio que sim. Aqui temos um enfoque na memória como uma força transformadora do presente, mas também, essa memória implica uma reconstrução do passado. Por isso há um lema no monumento: "construímos o passado para que os sonhos retornem". É uma frase significativa. Nós vamos ao passado, sabemos que a reconstrução do passado é intencional, é subjetiva, tem usos próprios. Não há objetividade na História, nem na memória. Ambos são feitos por sujeitos, por grupos sociais que estão buscando interpretar o que ocorreu, reivindicar suas vítimas, lutas e resistências. Nossa aposta inicial é no reconhecimento da dignidade das vítimas, mas também na transformação para o futuro, pela luta pela paz, pela compreensão de todo o horror dos assassinatos, mortes, massacres, desaparecimentos, todo o horror de décadas na Colômbia.Tudo isso clama por um "basta", por um "nunca mais". Isso significa a paz, não é fazer um monumento para que as pessoas venham a um muro das lamentações, mas que venham aprender, adquirir conhecimento, e também a afirmar suas convicções democráticas, humanistas dos Direitos Humanos e da busca de paz. Por isso colocamos tanta força na juventude como protagonista dos exercícios de memória. Queremos que eles sejam os principais sujeitos desses exercícios.

Dessa forma, podemos dizer que o projeto tem essa mescla de passado e de futuro, com ênfase em considerar o presente olhando para o passado, mas buscando a transformação. Todo o exercício de memória é presente, e tem propósitos políticos atuais. Isso é evidente, mas nem sempre é declarado. Se levarmos em consideração em que consiste o Memorial em Lima, que é um centro para a divulgação dos trabalhos da Comissão da Verdade, da luta contra o terrorismo e da derrota do 
Sendero Luminoso, então percebemos que o projeto tem um propósito político, um ponto de vista atual. Isso é o mesmo que se fez na Espanha e em outros lugares. Em geral, a memória que é feita dos períodos ditatoriais tem uma grande ênfase na reconstituição, no esclarecimento e menos ênfase em situações como a colombiana, onde se faz a memória em meio à guerra, em meio ao conflito, à atrocidade. Não é uma memória de um passado, é uma memória do que está ocorrendo todos os dias.

Eu creio que quem melhor tem conseguido expressar isso são os indígenas. Isso porque quando se discutiu uma lei chamada pelo governo de Ley de Victimas (Lei das Vítimas), há uns três anos, também se estipularam algumas normas em consultas com os povos indígenas e eles se negaram a olhar para a memória como sendo do conflito armado, senão como a memória da resistência, da luta dos povos. Quer dizer, deram um enfoque distinto à lei. Queriam a lei, mas fazer memória do conflito armado, dos enfrentamentos, dos levantes que ocorreram, bem como das circunstâncias históricas que levaram a uma construção de formas de exercício de poder na Colômbia, a uma economia baseada na violência física, na violência armada do poder, na contra violência dos subordinados. Creio que essa seja uma visão mais próxima do que temos assumido no Centro de Memória.

\section{Poderia falar mais sobre a Ley de Victimas?}

A lei 1448 tem vários componentes. Foi aprovada em Dezembro de 2011 e é uma lei nacional que possui vários decretos-leis submetidos a ela. Três desses decretos são para os povos indígenas, para povos afro-colombianos e para povos ciganos. Nessa lei há um primeiro capítulo sobre memória, que se beneficiou do processo de constituição do Centro de Memória. Por isso a lei apresenta discussões avançadas sobre o tema. Tem havido muitas discussões acerca do tipo de memória da qual estamos falando, sobre a qual período ela se refere, assim como acerca do conceito de vítima, ou seja, quando se faz memória em relação às vítimas, quando buscamos os direitos das vítimas e da sociedade, acerca do que estamos a nos referir exatamente. A lei define memória como um dos direitos das vítimas e da sociedade à verdade, ou seja, não como um direito autônomo, mas como um direito relacionado ao direito à verdade e em função desses dois coletivos: as vítimas e a sociedade. Isso me parece bastante acertado, porque existia uma tendência em se falar de memória das 
vítimas, memória para as vítimas, e de fato muitas pessoas lutam terrivelmente para que se ampliem os conceitos de Memória e de Vítima.

O conceito de Vítima que se busca na lei tem sido muito polêmico: falava-se acerca das vítimas do conflito armado e de violências associadas ao conflito armado, mas tudo permanecia como em um limbo. Quando começou, de fato, o conflito armado? A lei induz a pensar que o conflito teve início com o surgimento das guerrilhas, mas nesse ponto há um debate intenso. Foi realmente aí que o conflito teve início? Não terá sido nos anos 40, com a grande violência e tudo o que significou o esmagamento da insurreição, da rebelião Gaitanista, e tudo o que se seguiu no país a partir desse momento? Nesse período houve um massacre contínuo em quase todo o país, mas muitas pessoas acreditavam que esse evento tinha se dado muito antes. Produziu-se uma grande discussão acerca dessa questão, inclusive com a publicação de obras sobre o tema. Essa questão permaneceu, assim, em aberto na Ley de Victimas, da mesma forma que a própria identidade das vítimas.

Dizia-se que não se poderia considerar como vítimas nem os combatentes subversivos, nem seus familiares, mas que tampouco poderiam ser consideradas vítimas aqueles que haviam sido atingidos por organizações delinquentes comuns. Ao mesmo tempo, na Colômbia a Corte Constitucional e outras Cortes classificaram aos paramilitares como delinquentes comuns, então, ao dizer que nem os narcotraficantes, nem os paramilitares podem ser considerados como perpetradores de vítimas aos olhos da lei, estão retirando o direito a praticamente todo mundo, porque a maior parte das ações repressivas do Estado foram executadas com a cumplicidade e com a instrumentação de paramilitares e também de alianças com narcotraficantes. Dessa forma, há toda uma discussão acerca do conceito de vítima, e dos consequentes sentidos da memória nesse contexto.

Para essa discussão, têm contribuído também o Centro Nacional de la Memoria Histórica, o Museo Nacional de la Memoria Histórica e o Archivo de la Memoria, que têm estabelecido pautas no sentido de reparação simbólica das vítimas.

Você falou sobre guerra. Como utilizam essa palavra? Para quem está de fora, é difícil visualizar a guerra de que fala. Que significa esse termo para vocês? 
Bom, se nos retivermos somente aos confrontos violentos na Colômbia, que aconteceram em todo este período, dos últimos 30 anos, digamos, há um registro oficial do Estado, que se chama Registro Público de Vítimas, que é atualizado todos os dias e no qual se contabilizam homicídios políticos, desapropriações forçadas, desaparecimentos, torturas, sequestros e todo o tipo de modalidades de vítimas. Da última vez que o conferi, o total de vítimas reconhecidas, registradas com nome próprio, era de cerca de sete milhões e meio de pessoas registradas pelo Estado. Estas vítimas, em sua maioria, se deram entre o ano de 1995 e agora, quer dizer, nos últimos vinte anos. Estas cifras são subvalorizadas, porque é um registro oficial. Entre essas vítimas, podemos ver as que foram submetidas a desapropriações forçadas, e que, portanto, estão em territórios onde há confronto armado, que são forçadas a sair porque têm suas vidas em risco.

Então, veja: Há despejos forçados devido ao confronto armado na ordem de seis milhões e meio de vítimas. Além disso, há as vítimas de homicídios durante o mesmo período, as pessoas que morreram e cujas famílias que são consideradas vítimas pelo confronto. São novecentos e sessenta mil pessoas afetadas pelos homicídios e assim por diante: no que se refere a desaparecimentos forçados são cento e oitenta mil pessoas afetadas. E este é um número oficial! São trinta mil desaparecimentos diretos e a somarem-se as famílias afetadas, temos o total de cento e oitenta mil vítimas. Esses dados dizem respeito ao dia de hoje.

Podemos levar em consideração que estas cifras não afetam todo o país. Evidentemente o nível de confrontos varia de região para região. Tais confrontos, por exemplo, sofreram já um processo de neutralização na zona central do país. Entretanto, para cá migram todos os desapropriados pela guerra. Todos vêem a Bogotá. A capital tem hoje seiscentas mil pessoas fugidas dos campos e todos os dias chegam mais. No último ano chegaram cerca de cinquenta mil pessoas. Então, Bogotá não é mais cenário de confronto armado, mas é cenário de recrutamento de crianças e de jovens, de tráfico de armas, de todo o tipo de negócios. A força pública conseguiu tomar controle da zona central do país e poucas vezes se vêem cenários de confronto direto, como o detonar de uma bomba em algum edifício, o que às vezes ocorre, mas se fores a Medelín, ou outras cidades do país, a realidade é bem distinta. Há áreas no país que são prioritárias para os Estados Unidos, zonas de rotas de transporte, de recursos naturais tais como petróleo, carvão, ouro. Há uma disputa territorial nessas 
zonas. Neste momento, estamos em trégua, porque está a ocorrer um processo de negociação de paz, mas o cenário é esse.

Os mapas das guerrilhas são muito similares. Neles se sobrepõem guerrilhas, paramilitares, estrangeiros e exército. A única zona que o Estado conseguiu dominar é a zona central do país. Há, além disso, zonas onde não há guerrilha. Mas o exército em conjunto com os paramilitares conseguiram dominar a guerrilha porque é zona de carvão e petróleo. Por isso é que quando vais a Cartagena não vês guerra, sobretudo neste momento, em que há trégua, mas nos últimos cinco anos houve um período em que não se podia viajar pela Colômbia. As frentes guerrilheiras que estavam na zona de Bogotá e seus arredores foram derrotadas, em conflitos intensos, mas em 1998 a guerrilha quase entrou em Bogotá. Durante dez anos os confrontos contra as guerrilhas foram muito intensos nessa região. Por isso hoje as guerrilhas estão circunscritas a zonas fronteiriças e a regiões mais distantes, enquanto os paramilitares encontram-se próximos a alguns centros urbanos.

A Colômbia tem mil e cem municípios e a guerrilha tem presença em trezentos deles. Os paramilitares estão presentes em trezentos e cinquenta, e têm forte domínio em duzentos deles. Essas regiões às vezes se sobrepõem na presença de guerrilhas ou de paramilitares, somando cerca de quatrocentos municípios, ou seja, uma terça parte do país. Não é que na Colômbia haja guerra em toda a parte, mas essa situação afeta todo o país. Conta-se com um exército mais numeroso, em números relativos, comparado com outros países da América Latina, com um orçamento militar que afeta o produto interno bruto e que conta com excesso de gastos. Na América Latina o gasto militar direto está em torno de dois ou três por cento, em Colômbia, supera os cinco por cento. Isso altera todas as variáveis da economia. É esse o panorama do que vivemos no país.

\section{A guerra afeta, então, diretamente e a economia do país?}

Afeta o país e a toda a sociedade. Em Bogotá, ainda hoje, o exército chega em caminhões aos bairros de periferia e vai à procura de jovens para o serviço militar obrigatório. E com que argumento? É preciso lutar contra a guerrilha, contra a subversão. Há denuncias contra isso, porque é um sequestro de jovens para o serviço 
militar, feito à força. Isso acontece nas cidades, mas nos bairros pobres. Não o fazem em bairros modernos, no Colégio San Carlos, nos colégios de elite e de classe média, mas nos bairros pobres. Há ainda os desabrigados, seiscentos mil em Bogotá, o que significa nove por cento da população. É uma presença social visível. Ainda que Bogotá tenha conseguido alcançar, depois dos anos 90 , uma relativa consolidação e neutralização da presença da guerrilha e dos paramilitares, ainda é possível sentir a capital impactada por todas as dinâmicas do conflito. O mesmo ocorre em outras grandes cidades. Aqui se diz que é um fenômeno exclusivamente rural. Há muita gente que diz que temos uma guerra de guerrilha rural e um fenômeno de conflito armado rural. O cenário de operações e de conflito é, de fato, rural, e muito ocasionalmente urbano, mas há uma interdependência entre os processos.

Agora se fala de guerra porque os confrontos são armados e porque há uma atividade que envolve espaços muito importantes. Estamos a falar da terça parte dos municípios da Colômbia, para dar uma cifra. Além disso, há definições estatísticas acerca do número de mortes mínimo para se considerar uma situação de guerra. Não é uma categoria muito aceita, mas é a que assumiu oficialmente a Comissão de Memória Histórica, que fala de guerra. Para dar uma definição mais precisa, há guerra, há conflito armado interno, há violência sistemática. A partir de todas essas categorias é possível fazer uma leitura da situação colombiana.

\section{Quem são os paramilitares? São milícias civis?}

Sim, são civis. Tiveram varias fases históricas, entretanto. Havia os autorizados e dotados de força pública, como auxiliares na luta contra os insurgentes. Isso foi nos anos 60 e parte dos 70 , mas logo houve formações cada vez maiores, organizadas por narcotraficantes que foram formando exércitos e que entraram em aliança com unidades e com o equipamento da força pública, bem como com políticos e empresários e formaram um núcleo de grupos denominados narco-paramilitares, porque não se trata do paramilitarismo clássico, como um aparato anexo à força pública, mas sim grupos delinquentes de organizações criminosas, mas com ligações ao Estado e à força pública que atuam de maneira conjunta também na guerra antiinsurgente, mas o fazem por conveniência e por negócios. Há uma aliança oportunista que corrompe também o Estado, como praticou o Coronel Nord em Honduras, para 
combater os Sandinistas, que se armaram com o dinheiro do narcotráfico. Vigora a lógica de que para combater o inimigo pode-se aliar ao diabo.

Isso fez parte da guerra fria e de toda a política de contra-insurgência durante muito tempo, mas que aqui levou a que se consolidassem alianças com um grupo de narcotraficantes armados. Está aí a gênese dos grupos narco-paramilitares, forças armadas, elites de proprietários de terras e outros setores chamados de para-política e que formaram um complexo com propósitos de controle territorial, controle de negócios e de recursos e com uma ação contra-insurgente respondendo também a uma dinâmica de expansão, em um momento de ameaça da guerrilha frente a alguns grupos de pecuaristas, de empresários, de extorsão, etc. Então, se desencadeou todo um fenômeno com respaldo social muito grande, das classes médias e altas, gente com recursos que se sentia ameaçada e por isso dava seu consentimento, sua simpatia ou seu apoio econômico a esses grupos criminosos, a essas máfias. Isso progride até ao ponto em que hoje já se perdeu todo o discurso contra-insurgente. É mais uma máfia com tentáculos e articulada em muitos poderes, mas que cumpriu uma função de ordem, de submissão de populações e de combate às guerrilhas. Assim, passamos do paramilitarismo clássico ao narco-paramilitarismo.

\section{Em relação à categoria de vítima é possível pensar que as pessoas que fazem parte do exército são também vítimas?}

De acordo com o direito internacional humanitário, os combatentes têm direitos em meio à guerra de conflito interno. O protocolo II adicional à Convenção de Genebra não fala de guerra, fala de conflito armado interno e estabelece proibições no confronto militar. Algumas são restrições acerca das armas utilizadas. Armas de destruição em massa, por exemplo, são proibidas à luz do Direito Internacional. Um combatente, um soldado ou um guerrilheiro que é atingido por uma mina, é um ser humano e é considerado como vítima. Um guerrilheiro que é assassinado, morto por uma bomba, ou qualquer outro artefato explosivo, ou é atingido por armas químicas, é também vítima. O mesmo se passa aos que são rendidos e fuzilados fora de combate, aos que são rendidos como prisioneiros e submetidos a maus tratos ou tortura, ou a qualquer situação semelhante, todos são vítimas. Isso está definido no Direito Internacional. 
No Centro de la Memoria há quem reivindique a memória sendo do exército, ou seja, ocupando o lugar de perpetrador?

Sim, temos aqui entre os aliados com quem trabalhamos de maneira permanente desde o principio, a Asociación de Familiares de Policías y Soldados, que tem cadeiras, postos de investigação. Publicamos obras que falam acerca da sua situação de vítimas. Eles fazem parte do diálogo que temos que fazer e que fazemos permanentemente.

A Ley de Victimas traz uma definição distinta acerca dos militares. Na lei, todo o militar que seja atacado é vítima. Pelo fato de serem militares e terem sofrido qualquer agressão já são considerados vítimas do conflito ou vítimas para a lei. Por outro lado, a lei diz que os guerrilheiros não podem ser considerados vítimas, nem seus familiares. Se, por exemplo, um guerrilheiro é capturado e estando preso o matam, ele não é considerado vítima segundo a lei e tampouco seus familiares podem fazer qualquer reivindicação. É uma lei bastante assimétrica.

\section{Como estão correndo as negociações de paz?}

Avançaram muito, ao ponto que se já se fala sobre o fim do conflito. Há temas legais ainda para serem solucionados, mas penso que nos próximos meses já se vai falar sobre o fim do conflito, da ratificação dos acordos, das garantias e entramos na reta final. Ainda se pode por a perder o processo, entretanto. Neste país tem ocorrido situações peculiares, atentados, bombas, todo o tipo de provocações têm ocorrido quando se iniciam processos de paz, mas há uma dinâmica muito forte e não somente em contexto nacional. Por isso penso que o processo seguirá adiante e que no próximo ano se firmará um acordo de paz entre as FARC e o Governo.

\section{Há uma Justiça de Transição nesse processo?}

Sim, se estabelecerá uma jurisdição especial de paz. É parte do acordo. Também se estabelecerá um Tribunal de Paz no qual se utiliza o conceito de Justiça 
Restaurativa e nesse contexto, quem esteja implicado em crimes de lesa humanidade necessitará acudir ao tribunal, que terá um processo especial, com sanções de restrição da liberdade de militares, inclusive. Não será somente para os guerrilheiros, mas para todos: militares, políticos, empresários, todos os que tenham cometido crimes de lesa humanidade, crimes de guerra. Esses irão a tribunal e se estabelecerão benefícios conforme os acusados tenham contribuído para a Paz, para a Verdade e para a reconciliação do país.

\section{Acerca da Mesa de La Habana, quem são os atores dessa negociação de paz?}

Por um lado, está a guerrilha e seus comandantes, por outro, a delegação do Governo que é formada por militares, empresários e delegados diretos do governo e também representantes de alguns países que servem de garantia, além de outros que têm delegados na Mesa, como observadores. É um processo muito importante, porque tem delegados dos Estados Unidos, da Alemanha, e da União Europeia. Alguns representantes são muito próximos do Vaticano e outros colocam-se como facilitadores do processo, como a Noruega e Cuba, por um lado, e por outro Chile e Venezuela.

\section{Qual o papel do Centro nessa negociação?}

Nós fazemos um acompanhamento permanente do que está decorrendo em La Habana e propiciamos aqui espaços de reunião para que todos os setores que queiram contribuir com ideias, com informações, com mobilização para o processo de negociação, tenham espaço de encontro. Aqui fazem reuniões da cúpula campesina, do movimento sindical, de artistas, de jovens, de todo o tipo de grupos sociais. E fazemos também muitos trabalhos pedagógicos, cursos, conferências, todo o tipo de atividades, não somente aqui, mas também em outros espaços aliados para manter o debate e levar à participação. 


\section{Você participa diretamente das negociações?}

Não. A mesa ocasionalmente convoca certas instâncias, faz consultas sobre o tema das vítimas, sobre o tema agrário, sobre o tema das drogas, e se fazem reuniões convocadas pela Mesa de Negociación sob a responsabilidade das Nações Unidas e com a anuência nacional das diversas organizações que trazem elementos sobre os temas pontuais específicos, como o tema da justiça, o dos paramilitares, por exemplo. Então há pequenas reuniões consultivas, na medida em que permite o Regulamento. Eu já participei em outras oportunidades nas negociações, mas agora não. Mantenho somente uma colaboração acadêmica.

\section{Qual é, e de onde vem o orçamento do Centro de Memória?}

Todo o orçamento vem da cidade. Há alguns projetos pequenos nos quais temos tido apoio de cooperação, mas para coisas muito pontuais. Temos tido um orçamento, durante este período, de mais ou menos cinco milhões de pesos ao ano para funcionamento, sem contar com a construção do edifício, que conta com dois milhões de dólares aproximadamente, e mais o que temos recebido de pequenos projetos de cooperação, o que não chega a cinco por cento do total. Os restantes noventa e cinco por cento correspondem ao orçamento do Distrito.

\section{E com a mudança de governo, você acredita que isso vá se manter?}

Mudanças vão ocorrer, porque será um governo de um regime político diferente. Aqui tem governado partidos de esquerda durante todo o processo de construção do Centro. Agora vem um governo que é de coalizão, com um perfil distinto. Alguns dizem que é de Centro, outros dizem que é de Centro-direita, mas de toda forma, há um grande sentimento pela paz e um reconhecimento das iniciativas pelas vítimas e ao tema da memória. Tudo isso tem tido uma acolhida muito grande neste país, e eu estou muito seguro de que se vá dar continuidade a muitas coisas com seu próprio perfil, mas que os temas da memória para a paz e dos direitos humanos das vítimas terá continuidade. 


\section{O centro tem um arquivo?}

O Centro tem o Arquivo de Memória Oral, temos também os arquivos digitais disponíveis. Os arquivos físicos não estão em condições de serem disponibilizados. Inicialmente, pensamos em ter outro piso mais abaixo, mas era muito custoso, então temos os arquivos digitais e na WEB encontra-se disponível muita coisa.

\section{Muito obrigada!}

